\title{
Frequency of mutations and polymorphisms in borderline ovarian tumors of known cancer genes
}

Katherine Stemke-Hale ${ }^{1, \dagger}$, Kristy Shipman ${ }^{2, \dagger}$, Isidora Kitsou-Mylona ${ }^{3}$, David G de Castro ${ }^{4}$, Vicky Hird $^{5}$, Robert Brown ${ }^{2}$, James Flanagan ${ }^{2}$, Hani Gabra ${ }^{2}$, Gordon B Mills ${ }^{1}$, Roshan Agarwal² and Mona El-Bahrawy ${ }^{3,6}$

${ }^{1}$ Department of Systems Biology, MD Anderson, Houston, TX, USA; ${ }^{2}$ Department of Surgery and Cancer, Hammersmith Hospital, Imperial College London, London, UK; ${ }^{3}$ Department of Histopathology, Hammersmith Hospital, Imperial College London, London, UK; ${ }^{4}$ Molecular Diagnostics Laboratory, The Institute of Cancer Research and Royal Marsden NHS Foundation Trust, Sutton, UK; ${ }^{5}$ Department of Obstetrics and Gynaecology, Queen Charlottes Hospital, Imperial College Healthcare NHS Trust, London, UK and ${ }^{6}$ Department of Pathology, Faculty of Medicine, University of Alexandria, Alexandria, Egypt

\begin{abstract}
Borderline ovarian tumors represent an understudied subset of ovarian tumors. Most studies investigating aberrations in borderline tumors have focused on KRAS/BRAF mutations. In this study, we conducted an extensive analysis of mutations and single-nucleotide polymorphisms (SNPs) in borderline ovarian tumors. Using the Sequenom MassArray platform, we investigated 160 mutations/polymorphisms in 33 genes involved in cell signaling, apoptosis, angiogenesis, cell cycle regulation and cellular senescence. Of 52 tumors analyzed, 33 were serous, 18 mucinous and 1 endometrioid. KRAS c.35G $>$ A p.Gly12Asp mutations were detected in eight tumors (six serous and two mucinous), BRAF V600E mutations in two serous tumors, and PIK3CA H1047Y and PIK3CA E542K mutations in a serous and an endometrioid BOT, respectively. CTNNB1 mutation was detected in a serous tumor. Potentially functional polymorphisms were found in vascular endothelial growth factor (VEGF), $A B C B 1$, FGFR2 and PHLPP2. VEGF polymorphisms were the most common and detected at four loci. PHLPP2 polymorphisms were more frequent in mucinous as compared with serous tumors $(P=0.04)$, with allelic imbalance in one case. This study represents the largest and most comprehensive analysis of mutations and functional SNPs in borderline ovarian tumors to date. At least $25 \%$ of borderline ovarian tumors harbor somatic mutations associated with potential response to targeted therapeutics.

Modern Pathology (2013) 26, 544-552; doi:10.1038/modpathol.2012.194; published online 23 November 2012
\end{abstract}

Keywords: borderline; ovarian; sequenom; tumors

Borderline ovarian tumors account for $10 \%$ of all ovarian neoplasms predominantly affecting women in the reproductive age. ${ }^{1}$ Borderline ovarian tumors are histologically a heterogeneous group of slow growing, noninvasive tumors, the majority $(85 \%)$ of which present with stage I disease confined to the ovary. Overall, borderline ovarian tumors have a

Correspondence: Dr Roshan Agarwal, Department of Oncology, Hammersmith Hospital, Imperial College London, DuCane Road, London W12 0NN, UK.

E-mail: ragarwal@imperial.ac.uk or Dr Mona El-Bahrawy, Department of Histopathology, Hammersmith Hospital, Imperial College London, DuCane Road, London W12 0NN, UK.

E-mail: m.elbahrawy@imperial.ac.uk

${ }^{\dagger} \mathrm{KS}-\mathrm{H}$ and $\mathrm{KS}$ are the joint first authors.

Received 9 July 2012; revised 15 September 2012; accepted 19 September 2012; published online 23 November 2012 significantly better prognosis with over 95\% 5-year overall survival compared with $30-40 \% 5$-year overall survival rates for their invasive counterparts. ${ }^{1,2}$ Approximately $1 \%$ of borderline ovarian tumors show progression to invasive epithelial cancer. Non-resectable recurrent disease is responsible for the majority of disease-related deaths and present similar problems to invasive ovarian cancer, such as bowel obstruction and drug resistance. ${ }^{1}$

Prognostic factors in patients with borderline ovarian tumors and features potentially associated with recurrent and/or progressive disease include tumor type, patient age, FIGO stage, invasive implants, microinvasion in the primary tumor and micropapillary architecture. ${ }^{3-6}$ No single clinical or pathological feature or combination of features identify all adverse outcomes. ${ }^{7}$ Treatment options 
for patients with persisting/progressive disease are limited, ${ }^{8,9}$ with limited activity of currently available chemotherapeutic agents used in invasive ovarian cancers in the treatment of borderline ovarian tumors. ${ }^{9,10}$ New systemic therapeutic agents are therefore urgently required. ${ }^{1}$

Although the clinical and pathological characteristics of borderline ovarian tumors are well described, the molecular aspects are poorly understood. ${ }^{11,12}$ Borderline ovarian tumors have not been as extensively studied at a molecular level as invasive ovarian carcinomas, and knowledge of genetic abnormalities associated with borderline ovarian tumors is limited. Studies looking into gene mutations in borderline ovarian tumors have mainly been in comparison with invasive carcinoma and focused on TP53, BRAF and KRAS. ${ }^{13-16}$ TP53 mutations are not commonly associated with borderline ovarian tumors, in contrast to their high frequency in high-grade carcinoma. ${ }^{15}$ Conversely, KRAS and BRAF mutations are both much more common in borderline ovarian tumors and lowgrade serous carcinomas. ${ }^{13,17}$

In addition to KRAS, BRAF and TP53, a few studies have also investigated the frequency of PIK3CA, ${ }^{18}$ $B R C A 1,{ }^{19}$ EGFR ${ }^{20}{ }^{20}{ }^{2} N N B 1^{21}$ and $P T E N^{21}$ mutations in borderline ovarian tumors in comparison with invasive ovarian carcinomas. Gene amplifications have also been studied in borderline ovarian tumors, including ERBB2 (ref.22) and AKT2. ${ }^{23}$

In this study, we used the high-throughput Sequenom MassArray approach to investigate single-nucleotide mutations and polymorphisms in 33 genes in a cohort of borderline ovarian tumors to determine the frequency of genetic changes associated with borderline ovarian tumors (see Supplementary Appendix 1in the Supplemental Material).

\section{Materials and methods}

\section{Tumor Samples}

Frozen tissue from 52 borderline ovarian tumors was obtained from the Imperial College Healthcare NHS Trust Tissue Bank, Hammersmith Hospital. Ethics Committee approval for use of human tissue was obtained. Table 1 summarizes patients' age, tumor types and tumor stage.

\section{DNA Extraction}

DNA was extracted from fresh snap frozen tissue. An H\&E-stained section from the frozen tissue used for each specimen was examined to verify the content and the quality of the tissue analyzed. Briefly, tissue was homogenized in $180 \mu \mathrm{l}$ RTL buffer (Qiagen) using a TissueLyser (Tissuelyser I, Retsch, Leeds, UK) at $15 \mathrm{~Hz}$, for $20 \mathrm{~s}$. Supernatant containing disrupted tissue was transferred to a $1.5-\mathrm{ml}$ microfuge tube, $20 \mu \mathrm{l}$ Proteinase $\mathrm{K}$ was added and the
Table 1 Patient and tumor characteristics

\begin{tabular}{lr} 
Age (median, years) & 50 \\
\hline Tumor type & \\
Endometroid & 1 \\
Mucinous & 18 \\
Serous & 33 \\
FIGO stage & \\
IA & 22 \\
IC & 16 \\
IIA & 2 \\
IIC & 1 \\
IIIA & 1 \\
IIIB & 3 \\
IIIC & 1 \\
Unstaged & 6
\end{tabular}

sample incubated at $56{ }^{\circ} \mathrm{C}$ overnight. DNA was then extracted using the QIAamp DNA Mini kit (Qiagen) according to the manufacturer's protocol.

\section{Sequenom MassArray}

The list of genes, mutations and polymorphisms assessed by Sequenom are presented in Supplementary Appendix 1, Supplemental Material. PCR and extension primers were designed using Assay Design (Sequenom). PCR-amplified DNA was cleaned using EXO-SAP (Sequenom), and primer was extended by IPLEX chemistry, desalted using Clean Resin (Sequenom) and spotted onto Spectrochip matrix chips using a nanodispenser (Samsung). Chips were run in duplicate on a Sequenom MassArray MALDI-TOF MassArray system. Sequenom Typer Software and visual inspection were used to interpret mass spectra. Reactions where $>15 \%$ of the resultant mass ran in the mutant site in both reactions were scored as positive. Mutations and polymorphisms for a subset of samples and targets were confirmed by Sanger sequencing and pyrosequencing, respectively.

\section{Pyrosequencing}

PHLPP2 polymorphisms and allelic imbalance in tumors was assessed using pyrosequencing of genomic DNA. The primers for PHLPP2 amplification and sequencing were: 5'-AAACAAAGCATTGT GGGAACACT- $3^{\prime}$ (forward), 5'-biotin-AAACTACCAT CGCCCCTACATT- ${ }^{\prime}$ (reverse) and 5'-CTAAGAAGC TGTGCACAT-3' (sequencing). Initial PCR was performed using Jumpstart Taq (Sigma), $60{ }^{\circ} \mathrm{C}$ annealing, $2.5 \mathrm{mM} \mathrm{MgCl}, 200 \mathrm{nM}$ primer and $10 \mathrm{ng}$ genomic DNA. Pyrosequencing of PCR products was performed using PyroGold Reagent kit (Biotage, Uppsala, Sweden) according to the manufacturer's instructions. The individual genotypes of the rs61733127 (L1016S) polymorphism were estimated manually using the Pyro Q-CpG Software (Qiagen, UK)) with thresholds for TT $(<10 \% \mathrm{C})$, 
CT (40-60\% C) and CC (>90\% C). We used the quantitation of $\mathrm{C}$ vs $\mathrm{T}$ alleles in heterozygotes to identify tumors displaying loss of heterozygosity with a threshold of $10-40 \% \mathrm{C}$.

\section{Sanger Sequencing for KRAS}

Mutations in KRAS were verified using primers (forward: 5'-TTTGATAGTGTATTAACCTTATG-3' , reverse: 5'-GAGGTAAATCTTGTTTTAATA-3'), using $10 \mathrm{ng}$ DNA, $200 \mathrm{nM}$ primer, $2.5 \mathrm{mM} \mathrm{MgCl}$ and JumpStartTaq (Sigma) at $52{ }^{\circ} \mathrm{C}$ for 40 cycles. Sequencing was performed using the BigDye Terminator v3.1 Cycle Sequencing kit (Applied Biosystems). Cycle conditions were $94{ }^{\circ} \mathrm{C}$ for $1 \mathrm{~min}$ followed by 30 cycles of $94{ }^{\circ} \mathrm{C}$ for $10 \mathrm{~s}, 55^{\circ} \mathrm{C}$ for $15 \mathrm{~s}$ and $60{ }^{\circ} \mathrm{C}$ for $4 \mathrm{~min}$. PCR products were cleaned by EDTA-ethanol precipitation, resuspended in HiDi formamide and run on a $3730 \times 1$ DNA Analyzer (Applied Biosystems Ltd). Base calling, quality assessment and assembly were carried out using the Phred, Phrap, Polyphred, Consed software suite. All potential sequence variants were verified by manual inspection of the chromatograms.

\section{EGFR and PDGFRA Mutational Analysis}

EGFR mutations in exons 19-21 and PDGFRA mutations in exons 12 and 18 were analyzed by capillary electrophoresis single-strand conformation analysis (CE-SSCA) using a $3130 \times 1$ genetic analyzer (Life Technologies, Warrington, UK) and non-denaturing polymer at three different temperatures. Any conformation changes were subjected to bidirectional Sanger sequencing.

\section{Immunohistochemistry}

The expression of beta-catenin was evaluated by immunohistochemistry using the avidin-biotin immunodetection complex method. Two-micron-thick sections from formalin-fixed, paraffin-embedded tissue were prepared, deparaffinised and rehydrated. Endogenous peroxidase was blocked by incubation in hydrogen peroxide. Antigen retrieval was performed by microwaving in $0.01 \mathrm{M}$ citrate buffer $(\mathrm{pH}$ 6.0) at $750 \mathrm{~W}$ for $20 \mathrm{~min}$. Nonspecific binding was blocked with normal goat serum for 10 min. Tissue sections were then incubated with primary antibody for beta-catenin (BD Biosciences, 1:500 dilution) at room temperature for $60 \mathrm{~min}$. The sections were washed and then incubated with biotinylated goat anti-mouse immunoglobulin (Dako, 1:2000 dilution) for $30 \mathrm{~min}$, followed by streptavidin peroxidase for $30 \mathrm{~min}$. The slides were developed in DAB and followed by a hematoxylin counterstain. For each case, a section in which the primary antibody was replaced by phosphatebuffered saline was used as a negative control.

\section{Statistical Analysis}

The $\chi^{2}$ test was used to test for the presence of associations between the different gene mutations and polymorphisms and the histopathological features of tumors. A $P$-value of $<0.05$ was considered statistically significant. Statistical analysis was performed using SPSS (version 16.0, Chicago, IL, USA).

\section{Results}

Fifty-two borderline tumors were studied (Table 1 and Supplementary Appendix 2 in the Supplementary Material). The tumors included 33 serous $(63 \%), 18$ mucinous (35\%) and 1 endometrioid tumor $(2 \%)$. Six $(18 \%)$ of the serous tumors had a micropapillary component, two (6\%) showed microinvasion and seven (21\%) were associated with noninvasive implants. Of the mucinous tumors, two $(11 \%)$ showed microinvasion and four (22\%) showed intramucosal carcinoma. Patients aged from 26 to 82 years (median 50 years), with a median follow-up period of 3 years (range 2-7 years). One patient with a mucinous borderline ovarian tumor treated with unilateral oophorectomy developed a cyst on the other ovary that was detected on a follow-up scan 18 months after initial surgery. The patient did not undergo surgical removal of the cyst, so the histological nature of the cyst is unknown to us. None of the patients with serous and endometrioid tumors or other patients with mucinous tumors developed recurrence or disease progression.

Borderline endometrioid tumors are very rare, and this was an unusual opportunity to study the status of a large set of genes in this tumor.

\section{Gene Mutations}

Mutations were detected in 6 (KRAS, BRAF, PIK3CA, EGFR, PDGFRA and CTNNB1) of the 33 genes studied using the Sequenom assay (Table 2, Supplementary Appendix 2 in the Supplementary Material). KRAS c.35G $>$ A p.Gly12Asp mutations were detected in $8 / 52$ tumors (15\%), which included $6 / 33$ serous $(18 \%)$ and $2 / 18$ mucinous $(11 \%)$ tumors. $B R A F$ mutations were detected in only $2 / 52(4 \%)$ tumors, both of which were in serous tumors $(2 / 33$, $6 \%$ ). PIK3CA mutations were found in $2 / 52$ tumors (4\%). PIK3CA_E542K (heterozygous mutation-het) was present in $1 / 33(3 \%)$ serous tumor, and PIK3CA_H1047Y (het) was detected in the one borderline endometrioid tumor. PDGFRA_V824L (het) was detected in three tumors $(6 \%)$. These included $2 / 33$ serous $(6 \%)$ and $1 / 18$ (6\%) mucinous tumors. CE-SSCA and Sanger sequencing analysis of these samples failed to confirm the PDGFRA_V824L mutation, instead, 2/3 cases showed a synonymous polymorphism very near to that genomic position (c.2472C $>$ T; p.V834V). The third case showed 
Table 2 Frequency of mutations

\begin{tabular}{|c|c|c|c|}
\hline Mutation & Sequence & Genotype & Frequency $(\mathrm{n}=52)$ \\
\hline PIК3СА E542 & $1624 \mathrm{G}$ & GA & $\begin{array}{l}1 / 52(2 \%) \\
1 / 33 \text { serous }(3 \%)\end{array}$ \\
\hline $\begin{array}{l}\text { PIK3CA } \\
\text { H1047Y }\end{array}$ & & $\mathrm{TC}$ & $\begin{array}{l}1 / 52(2 \%) ; \\
1 / 1 \text { endometrioid }(100 \%)\end{array}$ \\
\hline KRAS G12 & $35 \mathrm{G}$ & $\begin{array}{l}\text { GA } \\
\text { GT }\end{array}$ & $\begin{array}{l}8 / 52(15 \%) \\
4 / 33 \text { serous }(12 \%) ; \\
1 / 18(6 \%) \text { mucinous } \\
2 / 33(6 \%) \text { serous; } \\
1 / 18(6 \%) \text { mucinous }\end{array}$ \\
\hline $\begin{array}{l}B R A F \text { V600E } \\
C T N N B 1 \text { S37 }\end{array}$ & $\begin{array}{c}1799 \mathrm{~T} \\
110 \mathrm{C}\end{array}$ & $\begin{array}{l}\text { AT } \\
\text { CG }\end{array}$ & $\begin{array}{l}2 / 52(4 \%) ; 2 / 33 \text { serous }(6 \%) \\
1 / 52(2 \%) ; 1 / 33 \text { serous }(3 \%)\end{array}$ \\
\hline
\end{tabular}

heavily degraded DNA and a wild-type conformation, which can also result in false priming.

Sequenom also identified EGFR L858R mutations in five cases. However, these mutations were not validated on Sanger sequencing.

CTNNB1_S37C (het) mutation was detected in 1 of the 33 serous tumors $(3 \%)$. Immunostaining of this sample showed nuclear localization of beta-catenin, a feature seen in the presence of beta-catenin mutations (Figure 1). This case was reviewed by two gynecological histopathologists and confirmed to be of the serous type.

Thirteen $(25 \%)$ of 52 tumors had at least one mutation in the genes tested (Supplementary Appendix 2, Supplementary Material). Eleven of the $13(85 \%)$ cases had a single mutation, while 2 cases $(15 \%)$ had two mutations (KRAS and CTNNB1 in one serous tumor and KRAS_G12_35G and PIK3CA_H1047Y in one endometrioid tumor). Table 3 summarizes the correlation between the presence of mutations and histopathological features of serous and mucinous tumors.

\section{Gene Polymorphisms}

Potential functional single-nucleotide gene polymorphisms (SNPs) were found in 4 of the 33 genes studied (Table 4, Supplementary Appendix 2, Supplemental Material). Only 4/52 (8\%) of tumors featured SNPs in only one of the genes tested, whereas 48/52 (92\%) tumors showed polymorphisms in two or more of the genes tested with the majority of genes being heterozygous (Table 4). The most common polymorphism observed was in VEGF in 50/ 52 borderline ovarian tumors (96\%), with SNPs detected at four loci. There were two or more VEGF SNPs in 24/33 serous tumors, $1 / 1$ endometrioid and 11/18 mucinous tumors. $A B C B 1$ polymorphisms were detected in $37 / 52$ borderline ovarian tumors (71\%), followed by FGFR2 polymorphisms in 29/52 borderline ovarian tumors (56\%).

Heterozygote PHLPP2 polymorphisms were detected in 14/52 (27\%) tumors. These included 5/ $33(15 \%)$ serous, $8 / 18$ mucinous $(44 \%)$ and one
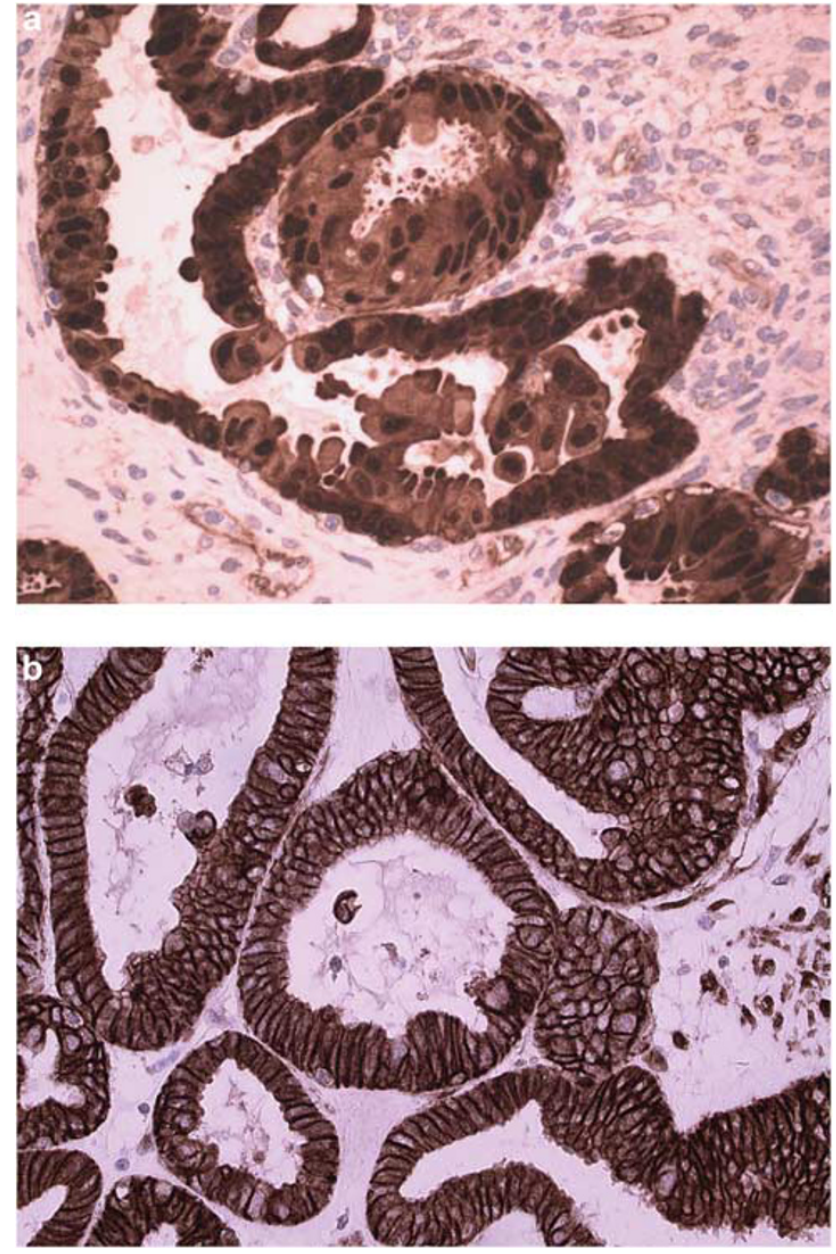

Figure 1 Expression of beta-catenin in a serous borderline ovarian tumor with beta-catenin mutation. In the serous borderline tumor with beta-catenin mutation there is cytoplasmic and notable nuclear localization with the absence of membranous staining $(\mathrm{A}: \times 400)$. This is in contrast to distinct membranous localization and absence of nuclear localization in a serous borderline ovarian tumor with wild-type beta-catenin (B: $\times 100)$.

endometrioid borderline ovarian tumor. Tumors with PHLPP2 polymorphisms included 2/4 (50\%) mucinous tumors with intramucosal carcinoma and 1/6 $(17 \%)$ serous tumor of the micropapillary type, and $1 / 2(50 \%)$ serous tumors with microinvasion $(50 \%)$.

Table 5 shows the correlation between polymorphisms and histopathological features of tumors. PHLPP2 polymorphisms were more common in mucinous tumors compared with serous BOTs; $44 \%(n=8 / 18)$ vs $15 \%(n=5 / 33), \chi^{2}(P=0.04)$.

\section{Validation of Gene Mutations and Polymorphisms in Selected Genes}

KRAS gene mutation status was assessed by direct Sanger sequencing in five cases, and confirmed the results of Sequenom MassArray in all cases. PHLPP2 polymorphisms were confirmed by pyrosequencing in all 52 cases. In addition, relative allelic quantification demonstrated evidence of allelic 
Table 3 Correlation between mutations and histopathological features of serous and mucinous tumors

\begin{tabular}{|c|c|c|c|c|c|c|c|c|}
\hline & \multicolumn{2}{|c|}{$\begin{array}{l}\text { Noninvasive implants } \\
(S)\end{array}$} & \multicolumn{2}{|c|}{$\begin{array}{l}\text { Micropapillary } \\
\text { component }(S)\end{array}$} & \multicolumn{2}{|c|}{ Microinvasion (S and $M$ ) } & \multicolumn{2}{|c|}{$\begin{array}{l}\text { Intramucosal } \\
\text { carcinoma }(M)\end{array}$} \\
\hline & + & - & + & - & + & - & + & - \\
\hline KRAS & $1 / 7(14 \%)$ & $5 / 26(19 \%)$ & $0 / 6(0 \%)$ & $6 / 27(22 \%)$ & $0 / 2 \mathrm{~S}(0 \%) 0 / 2 \mathrm{M}(0 \%)$ & $6 / 31 \mathrm{~S}(19 \%) 2 / 16 \mathrm{M}(13 \%)$ & $0 / 4(0 \%)$ & $2 / 14(14 \%)$ \\
\hline$B R A F$ & $0 / 7(0 \%)$ & $2 / 26(7 \%)$ & $0 / 6(0 \%)$ & $2 / 27(7 \%)$ & $0 / 2$ S $(0 \%) 0 / 2 \mathrm{M}(0 \%)$ & $2 / 31 \mathrm{~S}(6 \%) 0 / 16 \mathrm{M}(0 \%)$ & $0 / 4(0 \%)$ & $0 / 14(0 \%)$ \\
\hline РIКЗСА & $0 / 7(0 \%)$ & $1 / 26(4 \%)$ & $0 / 6(0 \%)$ & $1 / 27(4 \%)$ & $0 / 2 \mathrm{~S}(0 \%)$ 0/2 M (0\%) & $1 / 31 \mathrm{~S}(3 \%) 0 / 16 \mathrm{M}(0 \%)$ & $0 / 4(0 \%)$ & $0 / 14(0 \%)$ \\
\hline$\beta$-Catenin & $0 / 7(0 \%)$ & $1 / 26(4 \%)$ & $0 / 6(0 \%)$ & $1 / 27(4 \%)$ & $0 / 2$ S $(0 \%) 0 / 2 \mathrm{M}(0 \%)$ & $1 / 31 \mathrm{~S}(3 \%) 0 / 16 \mathrm{M}(0 \%)$ & $0 / 4(0 \%)$ & $0 / 14(0 \%)$ \\
\hline
\end{tabular}

Abbreviations: $\mathrm{S}=$ serous; $\mathrm{M}=$ mucinous

Table 4 Frequency of polymorphisms

\begin{tabular}{|c|c|c|c|c|c|c|c|}
\hline Polymorphism & $\begin{array}{c}\text { PHLPP2_L1016S_ } \\
\text { T3047C }\end{array}$ & $\begin{array}{l}\text { ABCB1- } \\
\text { G2677TA }\end{array}$ & $\begin{array}{c}\text { FGFR2_- } \\
\text { rs2981582_CT }\end{array}$ & $\begin{array}{c}\text { VEGF_5_ } \\
\text { 1154_GA_ref }\end{array}$ & $\begin{array}{l}V E G F \_5 \\
1498 \_C T\end{array}$ & $\begin{array}{l}\text { VEGF_5 } \\
2573 \_C A\end{array}$ & $\begin{array}{c}V E G F \_5 \_634 \_ \\
G C \_r e f\end{array}$ \\
\hline Serous & $5 / 33(15 \%)^{*}(\mathrm{CT})$ & $\begin{array}{l}23 / 33(70 \%) \\
\text { (T: 8; GT: } 15)\end{array}$ & $\begin{array}{l}\text { 18/33 (55\%) } \\
\text { (T: 8; CT: } 10)\end{array}$ & 13/33 (39\%) (GA) & $\begin{array}{l}26 / 33(79 \%) \\
\text { (T: 4; TC: } 22)\end{array}$ & 7/33 (21\%) (CA) & $\begin{array}{l}23 / 33(70 \%) \\
\text { (C: 4; CG: } 19)\end{array}$ \\
\hline Mucinous & $8 / 18(44 \%) *(\mathrm{CT})$ & $\begin{array}{l}\text { 13/18 (72\%) } \\
\text { (T: 4; GT: 9) }\end{array}$ & $\begin{array}{l}\text { 11/18 (61\%) } \\
\text { (T: 2; CT: } 9 \text { ) }\end{array}$ & $\begin{array}{c}9 / 18(50 \%) \\
(\mathrm{A}: 1 ; \mathrm{GA}: 8)\end{array}$ & $\begin{array}{l}\text { 12/18 (67\%) } \\
\text { (T: 3; TC: } 9 \text { ) }\end{array}$ & 1/18 (6\%) (A) & $\begin{array}{l}\text { 9/18 (50\%) } \\
\text { (C: } 2 ; \text { CG:7) }\end{array}$ \\
\hline Endometrioid & 1/1 (100\%) (CT) & 1/1 (100\%) (GT) & $0 / 1(0 \%)$ & $0 / 1(0 \%)$ & 1/1 (100\%) (TC) & $0 / 1(0 \%)$ & $1 / 1(100 \%)$ (CG) \\
\hline
\end{tabular}

Table 5 Correlation between polymorphisms and histopathological features of serous and mucinous tumors

\begin{tabular}{|c|c|c|c|c|c|c|c|c|}
\hline & \multicolumn{2}{|c|}{$\begin{array}{l}\text { Noninvasive } \\
\text { implants (S) }\end{array}$} & \multicolumn{2}{|c|}{$\begin{array}{l}\text { Micropapillary } \\
\text { component }(S)\end{array}$} & \multicolumn{2}{|c|}{ Microinvasion ( $S$ and $M$ ) } & \multicolumn{2}{|c|}{$\begin{array}{l}\text { Intramucosal } \\
\text { carcinoma }(M)\end{array}$} \\
\hline & + & - & + & - & + & - & + & - \\
\hline PHLPP2_L1016S_T3047C & $\begin{array}{c}0 / 7 \\
(0 \%)\end{array}$ & $\begin{array}{c}5 / 26 \\
(19 \%)\end{array}$ & $\begin{array}{c}2 / 6 \\
(33 \%)\end{array}$ & $\begin{array}{c}3 / 27 \\
(11 \%)\end{array}$ & $\begin{array}{c}1 / 2 \mathrm{~S}(50 \%) 0 / 2 \mathrm{M} \\
(0 \%)\end{array}$ & $\begin{array}{c}4 / 31 \mathrm{~S}(13 \%) 8 / 16 \mathrm{M} \\
(50 \%)\end{array}$ & $\begin{array}{c}2 / 4 \\
(50 \%)\end{array}$ & $\begin{array}{c}6 / 14 \\
(43 \%)\end{array}$ \\
\hline ABCB1_G2677TA & $\begin{array}{c}4 / 7 \\
(57 \%)\end{array}$ & $\begin{array}{l}19 / 26 \\
(73 \%)\end{array}$ & $\begin{array}{c}5 / 6 \\
(83 \%)\end{array}$ & $\begin{array}{l}18 / 27 \\
(67 \%)\end{array}$ & $\begin{array}{c}1 / 2 \mathrm{~S}(50 \%) 1 / 2 \mathrm{M} \\
(50 \%)\end{array}$ & $\begin{array}{c}22 / 31 \mathrm{~S}(71 \%) 12 / 16 \mathrm{M} \\
(75 \%)\end{array}$ & $\begin{array}{c}1 / 4 \\
(25 \%)\end{array}$ & $\begin{array}{l}12 / 14 \\
(86 \%)\end{array}$ \\
\hline FGFR2_rs2981582_CT & $\begin{array}{c}3 / 7 \\
(43 \%)\end{array}$ & $\begin{array}{l}15 / 26 \\
(58 \%)\end{array}$ & $\begin{array}{c}4 / 6 \\
(66 \%)\end{array}$ & $\begin{array}{l}13 / 27 \\
(48 \%)\end{array}$ & $\begin{array}{c}1 / 2 \mathrm{~S}(50 \%) 2 / 2 \mathrm{M} \\
(100 \%)\end{array}$ & $\begin{array}{c}17 / 31 \mathrm{~S}(55 \%) 9 / 16 \mathrm{M} \\
(56 \%)\end{array}$ & $\begin{array}{c}3 / 4 \\
(75 \%)\end{array}$ & $\begin{array}{c}8 / 14 \\
(57 \%)\end{array}$ \\
\hline VEGF_5_1154_GA_ref & $\begin{array}{c}1 / 7 \\
(14 \%)\end{array}$ & $\begin{array}{l}12 / 26 \\
(46 \%)\end{array}$ & $\begin{array}{c}2 / 6 \\
(33 \%)\end{array}$ & $\begin{array}{l}11 / 27 \\
(41 \%)\end{array}$ & $\begin{array}{c}1 / 2 \mathrm{~S}(50 \%) 1 / 2 \mathrm{M} \\
(50 \%)\end{array}$ & $\begin{array}{c}12 / 31 \mathrm{~S}(39 \%) 8 / 16 \mathrm{M} \\
(50 \%)\end{array}$ & $\begin{array}{c}2 / 4 \\
(50 \%)\end{array}$ & $\begin{array}{c}7 / 14 \\
(50 \%)\end{array}$ \\
\hline VEGF_5_1498_CT & $\begin{array}{c}6 / 7 \\
(86 \%)\end{array}$ & $\begin{array}{l}20 / 26 \\
(77 \%)\end{array}$ & $\begin{array}{c}5 / 6 \\
(83 \%)\end{array}$ & $\begin{array}{l}21 / 27 \\
(78 \%)\end{array}$ & $\begin{array}{c}2 / 2 \mathrm{~S}(100 \%) 2 / 2 \mathrm{M} \\
(100 \%)\end{array}$ & $\begin{array}{c}24 / 31 \mathrm{~S}(77 \%) 10 / 16 \mathrm{M} \\
(62 \%)\end{array}$ & $\begin{array}{c}3 / 4 \\
(75 \%)\end{array}$ & $\begin{array}{c}9 / 14 \\
(64 \%)\end{array}$ \\
\hline VEGF_5_2573_CA & $\begin{array}{c}1 / 7 \\
(14 \%)\end{array}$ & $\begin{array}{c}6 / 26 \\
(23 \%)\end{array}$ & $\begin{array}{c}1 / 6 \\
(17 \%)\end{array}$ & $\begin{array}{c}6 / 27 \\
(22 \%)\end{array}$ & $\begin{array}{c}2 / 2 \mathrm{~S} * *(100 \%) 0 / 2 \mathrm{M} \\
(0 \%)\end{array}$ & $\begin{array}{c}5 / 31 \mathrm{~S} * *(16 \%) 1 / 16 \mathrm{M} \\
(6.2 \%)\end{array}$ & $\begin{array}{l}0 / 4 \\
(0 \%)\end{array}$ & $\begin{array}{l}1 / 14 \\
(7 \%)\end{array}$ \\
\hline VEGF_5_634_GC_ref & $\begin{array}{c}5 / 7 \\
(71 \%)\end{array}$ & $18 / 26$ & $\begin{array}{c}4 / 6 \\
(66 \%)\end{array}$ & $\begin{array}{l}19 / 27 \\
(70 \%)\end{array}$ & $2 / 2 \mathrm{~S}(100 \%) 0 / 2 \mathrm{M}$ & 21/31 S 9/16 M & $\begin{array}{c}3 / 4 \\
(75 \%)\end{array}$ & $\begin{array}{c}6 / 14 \\
(43 \%)\end{array}$ \\
\hline
\end{tabular}

Abbreviations: $\mathrm{S}=$ serous; $\mathrm{M}=$ mucinous.

imbalance in one borderline ovarian tumor (Figure 2).

\section{Discussion}

We used the Sequenom MassArray technique to profile gene single-nucleotide mutations and polymorphisms in borderline ovarian tumors. We and others have previously demonstrated that the sensitivity of mass spectrometric methods exceeds that of traditional Sanger sequencing where the aberration must be present in $\sim 20 \%$ of the DNA present and is highly concordant with Sanger sequencing, pyrose- quencing and allele-specific PCR. ${ }^{24,25}$ Fifty-two tumors, representing the largest set of borderline ovarian tumors analyzed for mutational status, were studied for changes in 33 genes known to be involved in tumor pathology with the majority being potential targets, including genes in the RAS-RAF-MEK and RTK-phosphatidylinositol 3-kinase (PI3K)-AKT pathways.

Our study of borderline ovarian tumors shows that somatic mutations occur predominately in a subset of the genes studied. Overall, the frequency and pattern of mutations is consistent with borderline ovarian tumors showing more similarity and being potential precursors of Type I ovarian 

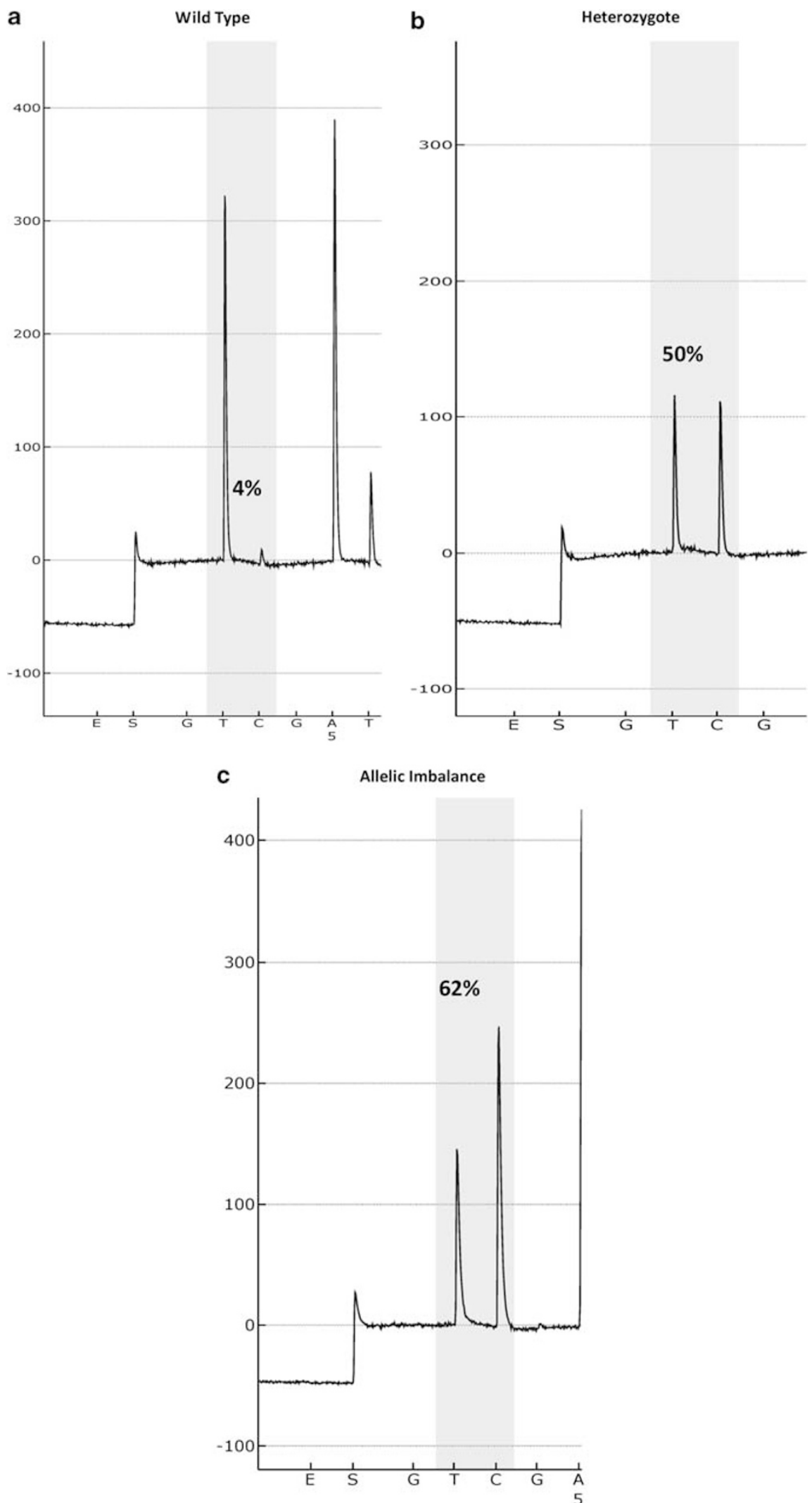

Figure 2 Pyrosequencing results for PHLPP2 polymorphisms. (a) Normal female genomic DNA homozygous for PHLPP2 major allele, (b) borderline ovarian tumor heterozygous for major and minor alleles and (c) borderline ovarian tumor with allelic imbalance for the minor allele. 
carcinoma. Jones et al comprehensively analyzed somatic mutations in low-grade serous carcinomas, by exome sequencing, and showed that the genes showing the most frequent mutations were $B R A F$ and $K R A S$, occurring in 38 and $19 \%$ of low-grade tumors, respectively, and a single case showed a PIK3CA mutation. Their mutational analysis demonstrates that point mutations are much less common in low-grade serous tumors of the ovary. ${ }^{17}$ In agreement with previous reports, in our study KRAS and BRAF mutations were the most common mutations detected. ${ }^{13,26-30}$ Mutations in decreasing order of frequency were identified in $K R A S, B R A F$, $P I K 3 C A$ and CTNNB1. Mutations in these genes are likely to perturb several signaling cascades as well as signaling networks involved in cell proliferation, survival and motility. The most frequent polymorphisms were found in the VEGF gene with four SNPs, followed by ABCB1, FGFR2 and PHLPP2. Allelic imbalance in favor of the minor allele of PHLPP2 was shown in one tumor suggesting selection of the minor allele may have a role in tumor development and progression.

Although the frequency of $R A S / R A F$ mutations in our cohort is relatively less than that in previous reports, ${ }^{16,31}$ the majority of detected mutations and polymorphisms seemed to focus on the RAS/RAF and $P I 3 K / A K T$ pathway and upstream growth factors and growth factor receptors. The Ras/Raf/ MEK/ERK and PI3K/PTEN/AKT signaling cascades interact and have critical roles in the transmission of signals from growth factor receptors to regulate gene expression and prevent apoptosis. These signaling and anti-apoptotic pathways can have different effects on growth, prevention of apoptosis and induction of drug resistance in cells of various lineages. Components of these pathways or upstream receptors are mutated or aberrantly expressed in human cancer and subjects of active drug development programs. ${ }^{32}$

One serous tumor had concurrent CTNNB1 and KRAS mutations, and an endometrioid borderline ovarian tumor PIK3CA and KRAS mutations. The finding of concordant mutations, despite the overall low frequency of mutations, suggests that additional genetic abnormalities are selected in the presence of mutations in KRAS and BRAF during the pathogenesis of borderline ovarian tumors. The presence of co-ordinate mutations suggests that alternative functions of the two genes are selected or that an aberration in a single node in the pathway does not engender sufficient pathway activation for tumor initiation or progression. CTNNB1 mutations have been reported previously in borderline ovarian tumors, exclusively in endometrioid but not serous borderline ovarian tumors as in the case here.

Deregulated signaling via the PI3K pathway is common in many cancer lineages. For example, PIK3CA is the most commonly mutated oncogene in uterine endometrioid carcinoma (UEC) ${ }^{33}$ and breast carcinomas. ${ }^{34}$ Mutations occur predominately in exon 20 (kinase domain) and exon 9 (helical domain) in breast cancer ${ }^{35-37}$ but in other sites in different lineages such as UEC. The frequency of PIK3CA hotspot mutations throughout the coding region of $3 \%$ is similar to the previously reported rate of $5 \%$ in borderline ovarian tumors. ${ }^{18}$ In endometrial carcinoma, PIK3CA mutations occur more frequently in KRAS-mutant samples (7/18, $39 \% ; P=0.06)$ than in KRAS wild-type $(17 / 90,19 \%)$ tumors. ${ }^{38}$ Consistent with these results, the only case of endometrioid borderline ovarian tumor harbored both KRAS and PIK3CA mutations. In contrast, and in keeping with published studies, $A K T$ mutations were not identified in borderline ovarian tumors. ${ }^{23}$

The value of SNPs, the most common form of genetic variation, as biomarkers in cancer for risk and prognosis is well established. There may be quantitative variation of transcript levels associated with distinct alleles or haplotypes found in promoters and coding regions of genes. These changes in expression owing to allelic variation are often associated with additional genomic or transcript modifications, such as DNA methylation or RNA editing. The Sequenom MassArray platform is a rapid, high-throughput platform that has been extensively used for SNP detection. ${ }^{39,40}$

The physiological role of VEGF in angiogenesis, and the activity of anti-VEGF agents, such as bevacizumab, in ovarian cancer, makes it an important target for evaluation in genetic association studies. ${ }^{41}$ Ovarian cancer patients with the VEGF $\mathrm{C}+936 \mathrm{~T}$ polymorphism $\mathrm{C} / \mathrm{T}$ genotype have a longer median PFS of 11.8 months, compared with those with the $\mathrm{C} / \mathrm{C}$ and $\mathrm{T} / \mathrm{T}$ genotype, with median PFS of 5.5 and 3.2 months, respectively. ${ }^{42}$ In our study, VEGF polymorphisms were the most common genetic variation detected, being present in $96 \%$ of tumors. Polymorphisms were found in four loci of the gene and $69 \%$ of the tumors had polymorphisms in two or more loci.

In this study, we detected polymorphisms and allelic imbalance in one of the members of the PHLPP gene family. The two members of this recently discovered family, PHLPP1 and PHLPP2, control the degree of agonist-evoked signaling by Akt and the cellular levels of PKC. ${ }^{43,44}$ Brognard et al identified a T-C SNP at position 3047 of PHLPP2, with a population frequency of $30 \%$, which results in an amino-acid change from Leucine to Serine at codon 1016 in the PP2C phosphatase domain with a reduction in phosphatase activity, thus driving constitutive phosphorylation of Akt. ${ }^{45}$

In this study, we detected this PHLPP2 polymorphism in $27 \%$ of tumors with a significant correlation with mucinous tumors as compared with serous. Pyrosequencing technology provides qualitative sequencing data simultaneously with quantitative allele dose information (allele quantification). Using pyrosequencing, we confirmed the presence of the PHLPP2 polymorphisms detected on the 
Sequenom platform, with loss of heterozygosity in one case. The association between PHLPP2 polymorphism and mucinous borderline ovarian tumors to our knowledge has not previously been reported, and may imply a role for the activation of AKT/PKC pathways in the genesis of this phenotype.

PDGFRA_V824L (het) was detected in three tumors (6\%). CE-SSCA and Sanger sequencing analysis of these samples failed to confirm the PDGFRA_V824L mutation, instead, 2/3 cases showed a synonymous polymorphism very near to that genomic position (c. $2472 \mathrm{C}>\mathrm{T}$; p.V834V). In most primer designs, care in taken to avoid annealing positions that overlap known polymorphic sites; however, if secondary structure interferes with primer design on the opposite strand, this is not always possible. Sequenom also identified EGFR L858R mutations in five cases. However, these mutations were not validated on Sanger sequencing. The discordance can be owing to the increased sensitivity of the mass spec-based sequencing; these mutations were detected at an allelic frequency of $15 \%$, which is below the detection level of Sanger sequencing.

Highly accurate MALDI-TOF-based detection provides unparalleled specificity and sensitivity for studies of genetic variation, including somatic mutation detection in heterogeneous samples. The limitations of this platform is that only 'hotspot' mutations are detectable. Although the Sequenom MassArray system is highly sensitive and accurate, before use in clinical practice, all mutations should be confirmed using an approved CLIA or equivalent assay in a laboratory medicine facility. Indeed, the EGFR and PDGFRA mutations detected by MALDITOF could not be confirmed by a validated clinical method based on CE-SSCA and Sanger sequencing. In the case of PDGFRA mutations, this discordance is likely due to the presence of a known polymorphism in the area adjacent to the mutation hotspot for which the test is designed in two out of three cases. Although our study was carried out on frozen tissue, these mutations and polymorphisms can in principle be detected on analyzing DNA extracted from formalin-fixed paraffin-embedded tissue, and hence can be used in routine practice. However, the degraded nature of some DNA samples derived from formalin-fixed paraffin-embedded tissue can cause artefacts in the analysis.

In summary, this study expands the repertoire of mutations and polymorphisms implicated in the pathogenesis of borderline ovarian tumors. The genes and pathways associated with these mutations and polymorphisms are clinically important with active drug development programs, as the trials using MEK inhibitors in low-grade serous carcinoma offer the opportunity for the implementation of similar targeted therapy in borderline ovarian tumors, an area of unmet clinical need. ${ }^{46}$ A larger sample size linked to clinical trials is required to establish that a gene mutation has a significant impact for prediction of response to therapy or prognosis. Future studies to determine if the presence of specific mutations predicts antitumor activity of targeted biological agents in borderline ovarian tumors are warranted.

\section{Acknowledgements}

The authors are grateful for support from the Imperial College Biomedical Research Centre and Experimental Cancer Medicine Centre grant from Cancer Research UK and the Department of Health. RA is supported by a Clinician Scientist Fellowship from Cancer Research UK. ME is supported by a grant from Ovacome.

\section{Disclosure/conflict of interest}

The authors declare no conflict of interest.

\section{References}

1 Morice P, Uzan C, Fauvet R, et al. Borderline ovarian tumour: pathological diagnostic dilemma and risk factors for invasive or lethal recurrence. Lancet Oncol 2012;13:e103-e115.

2 Sherman ME, Berman J, Birrer MJ, et al. Current challenges and opportunities for research on borderline ovarian tumors. Hum Pathol 2004;35:961-970.

3 Bell DA, Scully RE. Ovarian serous borderline tumors with stromal microinvasion: a report of 21 cases. Hum Pathol 1990;21:397-403.

4 Kennedy AW, Hart WR. Ovarian papillary serous tumors of low malignant potential (serous borderline tumors). A long-term follow-up study, including patients with microinvasion, lymph node metastasis, and transformation to invasive serous carcinoma. Cancer 1996;78:278-286.

5 McKenney JK, Balzer BL, Longacre TA. Patterns of stromal invasion in ovarian serous tumors of low malignant potential (borderline tumors): a reevaluation of the concept of stromal microinvasion. Am J Surg Pathol 2006;30:1209-1221.

6 Seidman JD, Kurman RJ. Ovarian serous borderline tumors: a critical review of the literature with emphasis on prognostic indicators. Hum Pathol 2000;31:539-557.

7 Longacre TA, McKenney JK, Tazelaar HD, et al. Ovarian serous tumors of low malignant potential (borderline tumors): outcome-based study of 276 patients with long-term ( $>$ or $=5$-year) follow-up. Am J Surg Pathol 2005;29:707-723.

8 Romagnolo C, Gadducci A, Sartori E, et al. Management of borderline ovarian tumors: results of an Italian multicenter study. Gynecol Oncol 2006;101:255-260.

9 Wong HF, Low JJ, Chua Y, et al. Ovarian tumors of borderline malignancy: a review of 247 patients from 1991 to 2004. Int J Gynecol Cancer 2007;17:342-349.

10 Faluyi O, Mackean M, Gourley C, et al. Interventions for the treatment of borderline ovarian tumours. Cochrane Database Syst Rev 2010;9:CD007696.

11 Micci F, Haugom L, Ahlquist T, et al. Genomic aberrations in borderline ovarian tumors. J Transl Med 2010;8:21. 
12 Shih Ie M, Kurman RJ. Molecular pathogenesis of ovarian borderline tumors: new insights and old challenges. Clin Cancer Res 2005;11:7273-7279.

13 Caduff RF, Svoboda-Newman SM, Ferguson AW, et al. Comparison of mutations of Ki-RAS and p53 immunoreactivity in borderline and malignant epithelial ovarian tumors. Am J Surg Pathol 1999;23:323-328.

14 Ho CL, Kurman RJ, Dehari R, et al. Mutations of BRAF and KRAS precede the development of ovarian serous borderline tumors. Cancer Res 2004;64:6915-6918.

15 Kupryjanczyk J, Bell DA, Dimeo D, et al. p53 gene analysis of ovarian borderline tumors and stage I carcinomas. Hum Pathol 1995;26:387-392.

16 Mayr D, Hirschmann A, Lohrs U, et al. KRAS and BRAF mutations in ovarian tumors: a comprehensive study of invasive carcinomas, borderline tumors and extraovarian implants. Gynecol Oncol 2006;103:883-887.

17 Jones S, Wang TL, Kurman RJ, et al. Low-grade serous carcinomas of the ovary contain very few point mutations. J Pathol 2012;226:413-420.

18 Nakayama K, Nakayama N, Kurman RJ, et al. Sequence mutations and amplification of PIK3CA and AKT2 genes in purified ovarian serous neoplasms. Cancer Biol Ther 2006;5:779-785.

19 Lakhani SR, Manek S, Penault-Llorca F, et al. Pathology of ovarian cancers in BRCA1 and BRCA2 carriers. Clin Cancer Res 2004;10:2473-2481.

20 Steffensen KD, Waldstrom M, Olsen DA, et al. Mutant epidermal growth factor receptor in benign, borderline, and malignant ovarian tumors. Clin Cancer Res 2008; 14:3278-3282.

21 Oliva E, Sarrio D, Brachtel EF, et al. High frequency of beta-catenin mutations in borderline endometrioid tumours of the ovary. J Pathol 2006;208:708-713.

22 Mayr D, Kanitz V, Amann G, et al. HER-2/neu gene amplification in ovarian tumours: a comprehensive immunohistochemical and FISH analysis on tissue microarrays. Histopathology 2006;48:149-156.

23 Bellacosa A, de Feo D, Godwin AK, et al. Molecular alterations of the AKT2 oncogene in ovarian and breast carcinomas. Int J Cancer 1995;64:280-285.

24 Stemke-Hale K, Gonzalez-Angulo AM, Lluch A, et al. An integrative genomic and proteomic analysis of PIK3CA, PTEN, and AKT mutations in breast cancer. Cancer Res 2008;68:6084-6091.

25 Fumagalli D, Gavin PG, Taniyama Y, et al. A rapid, sensitive, reproducible and cost-effective method for mutation profiling of colon cancer and metastatic lymph nodes. BMC Cancer 2010;10:101.

26 Cuatrecasas M, Erill N, Musulen E, et al. K-ras mutations in nonmucinous ovarian epithelial tumors: a molecular analysis and clinicopathologic study of 144 patients. Cancer 1998;82:1088-1095.

27 Diebold J, Seemuller F, Lohrs U. K-RAS mutations in ovarian and extraovarian lesions of serous tumors of borderline malignancy. Lab Invest 2003;83:251-258.

28 Giordano G, Azzoni C, D’Adda T, et al. Human papilloma virus (HPV) status, p16INK4a, and p53 overexpression in epithelial malignant and borderline ovarian neoplasms. Pathol Res Pract 2008;204:163-174.

29 Mok SC, Bell DA, Knapp RC, et al. Mutation of K-ras protooncogene in human ovarian epithelial tumors of borderline malignancy. Cancer Res 1993;53:1489-1492.
30 Sieben NL, Macropoulos P, Roemen GM, et al. In ovarian neoplasms, BRAF, but not KRAS, mutations are restricted to low-grade serous tumours. J Pathol 2004;202:336-340.

31 Singer G, Oldt R 3rd, Cohen Y, et al. Mutations in BRAF and KRAS characterize the development of lowgrade ovarian serous carcinoma. J Natl Cancer Inst 2003;95:484-486.

32 McCubrey JA, Steelman LS, Abrams SL, et al. Roles of the RAF/MEK/ERK and PI3K/PTEN/AKT pathways in malignant transformation and drug resistance. Adv Enzyme Regul 2006;46:249-279.

33 Hayes MP, Wang H, Espinal-Witter R, et al. PIK3CA and PTEN mutations in uterine endometrioid carcinoma and complex atypical hyperplasia. Clin Cancer Res 2006;12:5932-5935.

34 Campbell IG, Russell SE, Choong DY, et al. Mutation of the PIK3CA gene in ovarian and breast cancer. Cancer Res 2004;64:7678-7681.

35 Catasus L, Gallardo A, Cuatrecasas M, et al. PIK3CA mutations in the kinase domain (exon 20) of uterine endometrial adenocarcinomas are associated with adverse prognostic parameters. Modern Pathol 2008;21:131-139.

36 Catasus L, Gallardo A, Cuatrecasas M, et al. Concomitant PI3K-AKT and p53 alterations in endometrial carcinomas are associated with poor prognosis. Modern Pathol 2009;22:522-529.

37 Mori N, Kyo S, Sakaguchi J, et al. Concomitant activation of AKT with extracellular-regulated kinase $1 / 2$ occurs independently of PTEN or PIK3CA mutations in endometrial cancer and may be associated with favorable prognosis. Cancer Sci 2007;98:1881-1888.

38 Konstantinova D, Kaneva R, Dimitrov R, et al. Rare mutations in the PIK3CA gene contribute to aggressive endometrial cancer. DNA Cell Biol 2010;29:65-70.

39 Jurinke C, Denissenko MF, Oeth $\mathrm{P}$, et al. A single nucleotide polymorphism based approach for the identification and characterization of gene expression modulation using MassARRAY. Mut Res 2005;573:83-95.

40 Tang K, Oeth P, Kammerer S, et al. Mining disease susceptibility genes through SNP analyses and expression profiling using MALDI-TOF mass spectrometry. J Proteome Res 2004;3:218-227.

41 Perren TJ, Swart AM, Pfisterer J, et al. A phase 3 trial of bevacizumab in ovarian cancer. $N$ Engl J Med 2011;365:2484-2496.

42 Schultheis AM, Lurje G, Rhodes KE, et al. Polymorphisms and clinical outcome in recurrent ovarian cancer treated with cyclophosphamide and bevacizumab. Clin Cancer Res 2008;14:7554-7563.

43 Brognard J, Newton AC. PHLiPPing the switch on Akt and protein kinase $\mathrm{C}$ signaling. Trends Endocrinol Metab 2008;19:223-230.

44 Gao T, Brognard J, Newton AC. The phosphatase PHLPP controls the cellular levels of protein kinase C. J Biol Chem 2008;283:6300-6311.

45 Brognard J, Niederst M, Reyes G, et al. Common polymorphism in the phosphatase PHLPP2 results in reduced regulation of Akt and protein kinase C. J Biol Chem 2009;284:15215-15223.

46 Matulonis UA, Hirsch M, Palescandolo E, et al. High throughput interrogation of somatic mutations in high grade serous cancer of the ovary. PLoS One 2011;6: e24433.

Supplementary Information accompanies the paper on Modern Pathology website (http://www.nature.com/ modpathol) 